\title{
REVIEW
}

\section{Pain as a First Manifestation of Paraneoplastic Neuropathies: A Systematic Review and Meta-Analysis}

\author{
Panagiotis Zis · Antonella Paladini · Alba Piroli · Patrick C. McHugh • \\ Giustino Varrassi · Marios Hadjivassiliou
}

Received: May 10, 2017 / Published online: July 1, 2017

(C) The Author(s) 2017. This article is an open access publication

\begin{abstract}
Introduction: Paraneoplastic neurological syndromes (PNS) consist of a heterogeneous group of neurological disorders triggered by cancer. The aim of this systematic review is to estimate the reported prevalence of pain in patients with paraneoplastic peripheral neuropathy (PPN).

Methods: A systematic computer-based literature search was conducted on PubMed database. Results: Our search strategy resulted in the identification of 126 articles. After the eligibility

Enhanced content To view enhanced content for this article go to http://www.medengine.com/Redeem/ 8F98F0604C2A83B1..
\end{abstract}

P. Zis $(\bowtie) \cdot$ M. Hadjivassiliou

Academic Department of Neurosciences, Sheffield

Teaching Hospitals NHS Foundation Trust,

Sheffield, UK

e-mail: takiszis@gmail.com

P. Zis · M. Hadjivassiliou

Department of Neurology, University of Sheffield, Sheffield, UK

A. Paladini - A. Piroli

Department of MESVA, University of L'Aquila,

L'Aquila, Italy

P. C. McHugh

Centre for Biomarker Research, University of

Huddersfield, Huddersfield, UK

G. Varrassi

University of L'Aquila, L'Aquila, Italy assessment, 45 papers met the inclusion criteria. Full clinical and neurophysiological data were further extracted and involved 92 patients with PPN (54.5\% males, mean age $60.0 \pm 12.2$ years). The commonest first manifestation of PPN is sensory loss $(67.4 \%)$, followed by pain $(41.3 \%)$, weakness $(22.8 \%)$, and sensory ataxia $(20.7 \%)$. In $13.0 \%$ of the cases, pain was the sole first manifestation of the PPN. During the course of the PPN, $57.6 \%$ of the patients may experience pain secondary to the neuropathy.

Conclusions: Pain is very prevalent within PPN. Pain specialists should be aware of this. Detailed history-taking, full clinical examination, and requesting nerve conduction studies might lead to an earlier diagnosis of an underlying malignancy.

Keywords: Cancer; Pain; Paraneoplastic; Polyneuropathy

\section{INTRODUCTION}

Paraneoplastic neurological syndromes (PNS) consist of a heterogeneous group of neurological disorders triggered by cancer. These syndromes are caused by mechanisms other than metastases, metabolic or nutritional deficits, infections, coagulopathy, or side effects of cancer treatment such as chemotherapy. The discovery that many PNS are associated with antibodies against neural antigens expressed by 
the tumor (antineural antibodies) has suggested that PNS are immune-mediated [1].

The recommended diagnostic criteria for PNS [2] suggest that the cancer has to develop within 5 years of the diagnosis of the neurological disorder. This time period has been based on reports showing that in the majority of cases the interval between the PNS and the diagnosis of cancer is less than 5 years.

Paraneoplastic peripheral neuropathy (PPN) is one of the commonest PNS reported. The aim of this paper is to systematically review the presenting manifestations of patients with PPN and establish the reported prevalence of pain. This article follows on from the editorial introduction "Painful Peripheral Neuropathy and Cancer" (doi:10.1007/s40122-017-0077-2).

\section{METHODS}

\section{Literature Search Strategy}

A systematic computer-based literature search was conducted on April 6th, 2017 on PubMed database. For the search, we used three Medical Subject Headings (MeSH) terms. Term A was "neuronopathy" or "ganglionopathy" or "neuropathy", term B was "paraneoplastic" and term C was "first manifestation" or "first symptom" or "initial symptom" or "first manifestations" or "first symptoms" or "initial symptoms" or "presenting symptom" or "presenting symptoms" or "pain" or "painful". Limitations included language to be English and full text to be available. We also perused the reference lists of the papers in order to find papers not found through the search strategy.

\section{Inclusion and Exclusion Criteria}

To be included in the review, the articles had to meet the following criteria:

(1) To involve single cases or cases series with PPN.

(2) To study human adult subjects.

The following exclusion criteria were applied:

(1) Book chapters, reviews, letters to the editor and editorials that did not provide new data.
(2) Papers referring only to autonomic neuropathy.

(3) Papers referring only to cranial neuropathies.

(4) Papers referring only to small fiber neuropathies.

(5) Papers referring to POEMS (Polyneuropathy, organomegaly, endocrinopathy, M-protein and skin changes) syndrome.

(6) Papers referring to motor neuron disease.

(7) Papers providing incomplete clinical or neurophysiological data about the single cases/case series.

\section{Data Extraction}

Data were extracted from each study in a structured coding scene using Microsoft Excel and included information on the article identification, year of publication, evaluation period, total number of subjects, gender, age, first manifestation of the PPN, presence of pain secondary to the neuropathy, neurophysiological type of neuropathy, course of symptoms, type of cancer, and presence of anti-neuronal antibodies.

We used the International Association for the Study of Pain (IASP) definitions to classify pain as neuropathic or not.

This article is based on previously conducted studies and does not involve any new studies of human or animal subjects performed by any of the authors.

\section{Statistical Analyses}

A database was developed using the IBM SPSS Statistics (version 23.0 for Mac). Frequencies and descriptive statistics were examined for each variable. The primary outcomes of interest were the proportion of patients who experienced pain as a first manifestation of the PPN and the proportion of patients who experienced pain during their PNS. Further comparisons between groups were made using Student's $t$ test for continuous data and Chisquare test for categorical data. A value of $P<0.05$ was considered to be statistically significant. 


\section{RESULTS}

\section{Search Results}

This search strategy resulted in the identification of 126 articles. After the eligibility assessment, 81 articles were excluded. In total, 45 papers met the inclusion criteria and were used for this review [3-47]. These studies were published between 1984 and 2017. Figure 1 illustrates the study selection process.

Full clinical and neurophysiological data were further extracted from 42 papers and involved 92 patients with PPN (54.5\% males). The age of the patients ranged from 18 to 81 years (mean $60.0 \pm 12.2$ years). The demographic and clinical characteristics of these patients are summarized in Table 1.
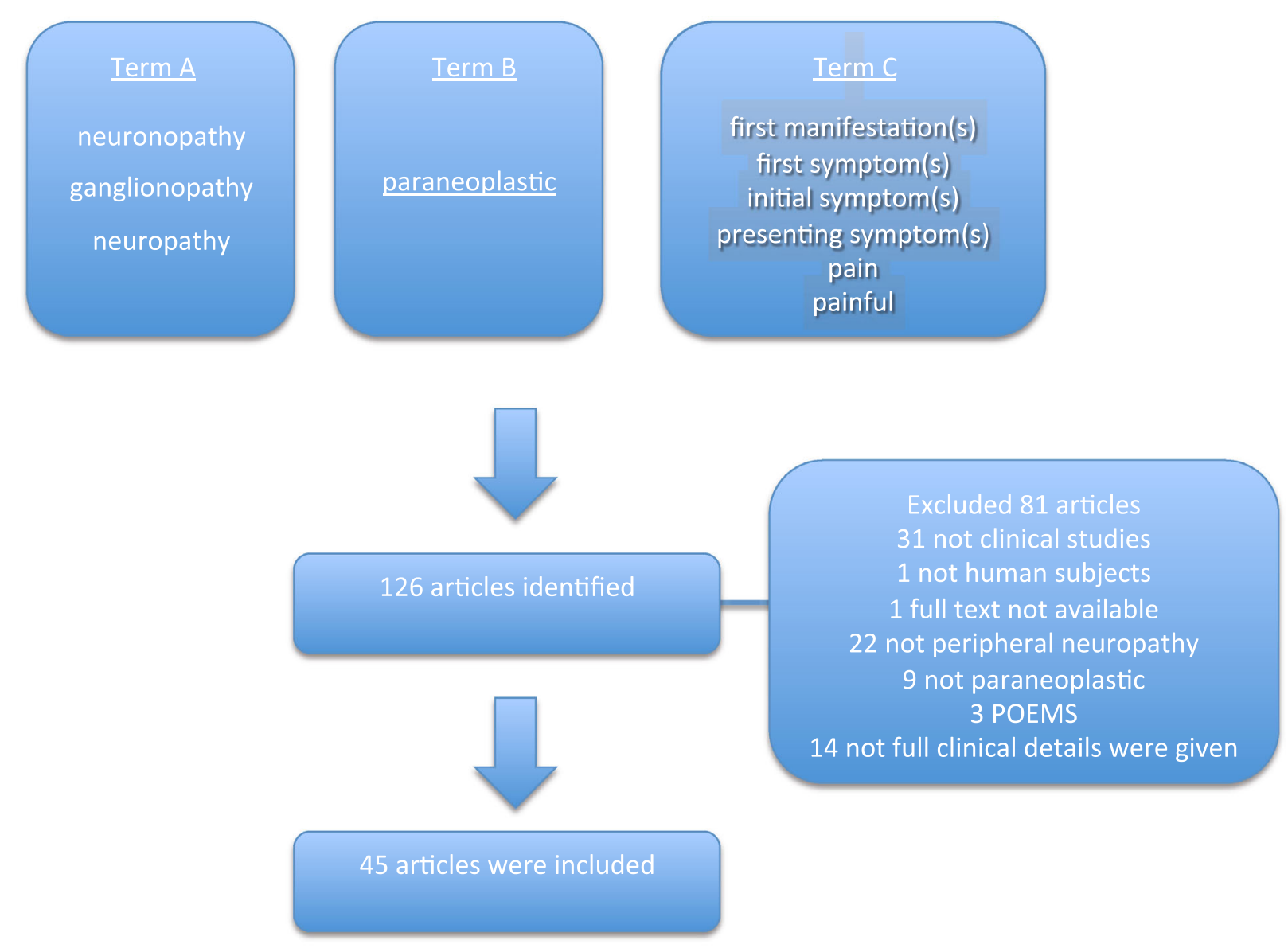

Fig. 1 PRISMA chart

\section{Epidemiological Characteristics of PPN}

Although PPN is said to be the commonest PNS (34.9\%), followed by encephalomyelitis (23.8\%) and cerebellar degeneration (20.6\%) [45], there is sparse epidemiological data on the prevalence of neurophysiologically confirmed PPN. The reasons for this are two-fold. The available studies to date are either in cohorts of patients with known malignancy and neuropathic symptoms or in patients who are seropositive for well-characterized paraneoplastic antibodies. A correct prevalence study of PPN should include a large cohort of patients with newly diagnosed malignancy all of whom should be evaluated for the presence of PN with nerve conduction studies, even in the absence of neuropathic symptoms and paraneoplastic antibodies. 
Table 1 Descriptive of studies included in the meta-analysis

\begin{tabular}{|c|c|}
\hline Parameter & Value \\
\hline Number of papers ${ }^{a}$ & 42 \\
\hline \multicolumn{2}{|l|}{ Type of papers } \\
\hline Case report $(\%)$ & $29(75.0)$ \\
\hline Case series (\%) & $13(25.0)$ \\
\hline Total number of patients & 92 \\
\hline Male:female & $3: 2$ \\
\hline Mean age, in years (SD) & $60.0(12.2)$ \\
\hline \multicolumn{2}{|l|}{ Presenting manifestations (\%) } \\
\hline Ataxia & $19(20.7)$ \\
\hline Sensory deficit & $62(67.4)$ \\
\hline Pain & $38(41.3)$ \\
\hline Weakness & $21(22.8)$ \\
\hline Pain at any point (\%) & $53(57.6)$ \\
\hline \multicolumn{2}{|l|}{ Type of pain (\%) } \\
\hline Neuropathic & $51(96.2)$ \\
\hline Nociceptive & $2(3.8)$ \\
\hline \multicolumn{2}{|l|}{ Type of neuropathy (\%) } \\
\hline Axonal & $80(87.0)$ \\
\hline Symmetrical sensorimotor & $21(22.8)$ \\
\hline Symmetrical sensory & $21(22.8)$ \\
\hline Sensory ganglionopathy & $25(27.2)$ \\
\hline Mononeuritis multiplex & $6(6.5)$ \\
\hline Pure motor & $7(7.6)$ \\
\hline Demyelinating & $12(13.0)$ \\
\hline \multicolumn{2}{|c|}{ Temporal evolution of neuropathy (\%) } \\
\hline Acute & $12(13.0)$ \\
\hline Sub-acute & $59(64.1)$ \\
\hline Progressive/chronic & $21(22.8)$ \\
\hline \multicolumn{2}{|l|}{ Type of malignancy (\%) } \\
\hline Lung & $42(45.7)$ \\
\hline Mediastinal & $4(4.3)$ \\
\hline Hematological & $15(16.3)$ \\
\hline
\end{tabular}

Table 1 continued

\begin{tabular}{ll}
\hline Parameter & Value \\
\hline Gastro-intestinal & $11(12.0)$ \\
Gynecological & $8(8.7)$ \\
Other & $6(6.5)$ \\
Unknown primary & $6(6.5)$ \\
Anti-Hu antibodies ${ }^{b}(\%)$ & $47(61.8)$ \\
\hline$S D$ standard deviation & \\
${ }^{a}$ Three more papers provided useful information on \\
epidemiology and were used in the review, but they did not \\
provide full clinical data on individual cases \\
b Tested in 76 patients
\end{tabular}

Lucchinetti et al. [47] estimated that out of 162 patients seropositive for anti-Hu antibodies (anti-neuronal antibodies usually associated to small-cell lung carcinoma), $72.8 \%$ presented with neuropathic symptoms. Most commonly, the patients presented with pure sensory (40.1\%), followed by mixed sensory and motor (30.2\%) and pure motor symptoms (2.4\%) [47]. However, no neurophysiological data were provided in this study.

In another series of 150 patients with a biopsy confirmed SCLC, Elrington et al. [6] estimated that the prevalence of sensory symptoms was $16 \%$ and the prevalence of motor symptoms $44 \%$. However, a definite neuropathy was confirmed with nerve conduction studies only in one patient $(0.7 \%$ of the total study population).

Graus et al. [46] presented a series of 200 patients, seropositive for anti-Hu antibodies, and estimated that $54 \%$ were present with predominantly sensory neuropathy and $4.5 \%$ with sensorimotor neuropathy. However, no information was given about whether nerve conduction studies were done in all patients, and what type of neuropathy these patients presented with.

\section{Clinical Manifestations of PPN}

The commonest early manifestation of PPN is sensory loss $(67.4 \%)$, followed by pain $(41.3 \%)$, weakness $(22.8 \%)$, and sensory ataxia $(20.7 \%)$. 
In $39.1 \%$ of the cases, the presenting complaints included more than one symptom. However, in $13.0 \%$ of the cases, pain was the sole first manifestation of the PPN. During the course of the PPN, $57.6 \%$ of the patients reported pain secondary to the neuropathy. In the majority of these patients $(96.2 \%)$, the pain was directly related to the neuropathy (considered as neuropathic) as described in the papers included in this review; however no validated tools were used to systematically assess and record other neuropathic symptoms accompanying pain. A minority of patients reported pain indirectly related to the neuropathy (not neuropathic), secondary to painful muscle cramps.

\section{Temporal Evolution of PPN and Pain}

Most reports classified PPN as acute, sub-acute or chronic/progressive. Acute were those neuropathies that evolved within 1 month, sub-acute were those that evolved between 1 and 6 months, and chronic the neuropathies that slowly kept progressing beyond 6 months. Based on these reports, we estimated that PPN are sub-acute in the majority of cases (64.1\%), followed by chronic (22.8\%) and acute (13.0\%).

\section{Neurophysiological Types of PPN and Pain}

Large fiber neuropathy can be axonal or demyelinating. In axonal neuropathy, axons are affected usually in proportion to their length (length dependent). In demyelinating neuropathy, the myelin sheath around axons is affected, and as a result, the ability of the axons to speedily conduct electrical impulses is impaired. The latter leads to slow or no conduction (conduction block). Sensory neuronopathy, or ganglionopathy, is another large fiber peripheral neuropathy, in which the cell bodies of the sensory neurons located in the dorsal root ganglia are affected. Finally, in pure motor neuropathy, there is involvement of only the lower motor neurons [48].

Demyelinating neuropathies were reported in $13 \%$ of PPN cases. Among the axonal PPN (87\%), the most common neurophysiological type was asymmetrical sensory ganglionopathy
(27.2\%), followed by symmetrical sensorimotor neuropathy $(23.9 \%)$, symmetrical sensory neuropathy $(21.7 \%)$, pure motor neuropathy $(7.6 \%)$, and mononeuritis multiplex (6.5\%). Figure 2 illustrates how common is pain based on the neurophysiological type of the PPN.

Though rare, the most painful type of PPN is mononeuritis multiplex. Mononeuritis multiplex is known to occur in many illnesses including certain types of systemic vasculitis [49]. Indeed, in the majority of patients with paraneoplastic mononeuritis multiplex a nerve biopsy was performed, showing evidence for vasculitis [36, 39].

Although pure motor neuropathy is the least common, it can still be painful. The major difference in the pain reported in such cases is that it is muscular in nature, most commonly because of cramps [40].

\section{Paraneoplastic Antibodies and Painful PPN}

Out of 76 patients with painful PPN tested for anti-Hu antibodies, 47 were positive (61.8\%). Other antibodies that have been associated with PPN are anti-amphiphysin and anti-CV2 antibodies. Interestingly enough, patients with anti-Hu antibodies were more likely to present with pain as a first manifestation compared to patients without anti-Hu antibodies (53.2 vs. $24.1 \%, p=0.013)$. Also, patients with anti-Hu antibodies were more likely to present with pain secondary to the PPN at any point compared to patients without anti-Hu antibodies (74.5 vs. $41.4 \%, p=0.004)$.

\section{Cancer Types and Painful PPN}

Lung cancer was the commonest cause of PPN $(45.7 \%)$, followed by hematological malignancies $(16.3 \%)$ and gastro-intestinal tract malignancies $(12.0 \%)$. The majority of patients seropositive for anti-Hu had lung cancer $(66.0 \%)$. Detailed data regarding type of malignancy are shown in Table 1 . Cancer type was not related significantly to pain either as a first manifestation or during the course of the PPN $(p>0.05)$. 


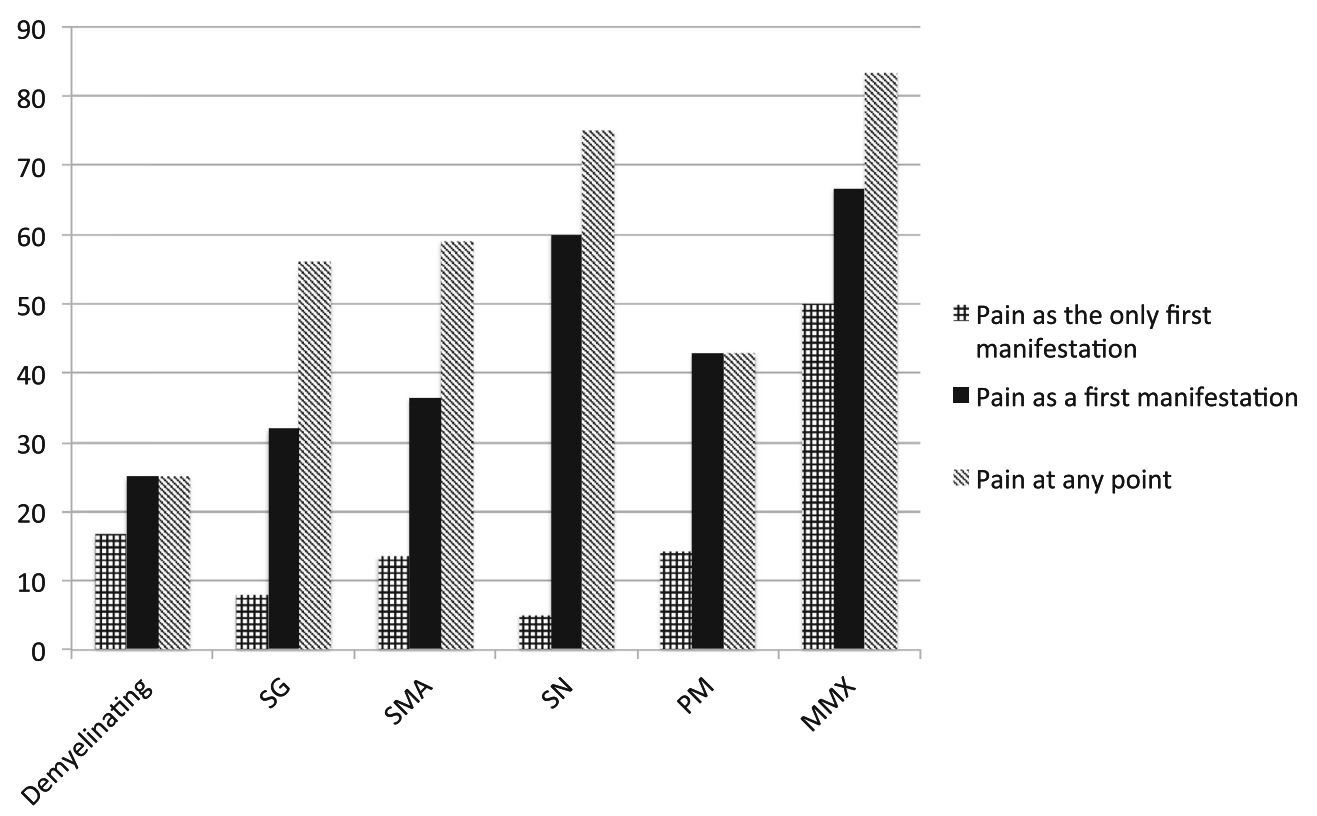

Fig. 2 Pain as a symptom among the different neurophysiological types of paraneoplastic peripheral neuropathies given in percentages. $S G$ sensory

\section{PPN and Cancer Relapse}

PNS can be the first manifestation of cancer relapse $[8,17,20]$ and they often precede the clinical or radiological diagnosis of a local relapse or distant metastases. Patients with a history of cancer presenting with peripheral neuropathic pain, not otherwise explained, can be diagnosed with PNS when circulating paraneoplastic antibodies are detected or a PET scan is positive.

\section{Management}

Management of pain as a result of paraneoplastic neuropathy does not differ from the published guidelines on the management of neuropathic pain [50]. However, it is commonly reported that treatment for the underlying malignancy (including tumor resection and/or chemotherapy) can improve the symptoms $[3,11,28,30,37]$.

\section{CONCLUSIONS}

This systematic review and meta-analysis indicates the following key points: ganglionopathy, SMA sensorimotor axonal neuropathy, $S N$ symmetrical sensory neuropathy, $P M$ pure motor neuropathy, $M M X$ mononeuritis multiplex

(1) Pure sensory neuropathy (sensory ganglionopathies and symmetrical sensory neuropathies) is the commonest form of PPN reported. A full neurophysiological assessment is therefore advisable in all suspected cases. Such a finding may prompt searching for an underlying malignancy.

(2) The commonest first manifestation of PPN is sensory loss $(67.4 \%)$, followed by pain $(41.3 \%)$, weakness $(22.8 \%)$, and sensory ataxia $(20.7 \%)$.

(3) Pain is prevalent in PPN, as almost three out of five patients with PPN will experience peripheral neuropathic pain at some point in the course of the PNS. The majority of the patients will experience neuropathic pain, but patients with pure motor neuropathies also experience pain secondary to cramps.

(4) One out of seven patients with PPN will experience pain as the sole manifestation. Therefore, pain specialists should be aware that they may be the first to encounter patients whose pain may be a paraneoplastic phenomenon. Therefore, detailed 
history taking, full clinical examination, and neurophysiological assessment-especially of sub-acute onset and of unknown etiology-may lead to an earlier diagnosis of an underlying malignancy.

(5) Testing for paraneoplastic antibodies (i.e., anti-Hu and anti-CV2), especially in sensory neuropathies that evolve sub-acutely, might also be helpful in earlier diagnosis of a PPN.

(6) PNS can occur as part of cancer relapse and pain can be the first manifestation in such cases. Therefore, patients with a past history of malignancy who present with neuropathic symptoms, including pain and have evidence of a PN on neurophysiology should be investigated further for a possible relapse. A PET scan might be useful in the earlier diagnosis of PNS [27].

(7) Among the papers included in this review, different terms have been used to describe the presenting symptoms. The use of validated tools [51] for assessing the presence of pain and the quality of the related characteristics might be useful for future prospective studies.

\section{ACKNOWLEDGEMENTS}

No funding or sponsorship was received for this study or publication of this article. All named authors meet the International Committee of Medical Journal Editors (ICMJE) criteria for authorship for this manuscript, take responsibility for the integrity of the work as a whole, and have given final approval for the version to be published. Panagiotis Zis has conceptualized the review. Panagiotis Zis carried out the systematic literature review and wrote the manuscript. Antonella Paladini, Alba Piroli, Patrick C. McHugh, Giustino Varrassi, and Marios Hadjivassiliou revised and critically appraised the manuscript.

Disclosures. Panagiotis Zis, Antonella Paladini, Alba Piroli, Patrick C. McHugh, Giustino Varrassi and Marios Hadjivassiliou have nothing to disclose.
Compliance with Ethics Guidelines. This article is based on previously conducted studies and does not involve any new studies of human or animal subjects performed by any of the authors.

Open Access. This article is distributed under the terms of the Creative Commons Attribution-NonCommercial 4.0 International License (http://creativecommons.org/licenses/ by-nc/4.0/), which permits any noncommercial use, distribution, and reproduction in any medium, provided you give appropriate credit to the original author(s) and the source, provide a link to the Creative Commons license, and indicate if changes were made.

\section{REFERENCES}

1. Darnell RB, Posner JB. Paraneoplastic syndromes involving the nervous system. $\mathrm{N}$ Engl $\mathrm{J}$ Med. 2003;349(16):1543-54.

2. Graus F, Delattre JY, Antoine JC, Dalmau J, Giometto B, Grisold W, Honnorat J, Smitt PS, Vedeler Ch, Verschuuren JJ, Vincent A, Voltz R. Recommended diagnostic criteria for paraneoplastic neurological syndromes. J Neurol Neurosurg Psychiatry. 2004;75(8):1135-40.

3. Donofrio PD, Albers JW, Greenberg HS, Mitchell BS. Peripheral neuropathy in osteosclerotic myeloma: clinical and electrodiagnostic improvement with chemotherapy. Muscle Nerve. 1984;7(2):137-41.

4. Gherardi R, Gaulard P, Prost C, Rocha D, Imbert M, Andre C, Rochant H, Farcet JP. T-Cell lymphoma revealed by a peripheral neuropathy: a report of two cases with an immunohistologic study on lymph node and nerve biopsies. Cancer. 1986;58(12):2710-6.

5. Oh SJ, Slaughter R, Harrell L. Paraneoplastic vasculitic neuropathy: a treatable neuropathy. Muscle Nerve. 1991;14(2):152-6.

6. Elrington GM, Murray NM, Spiro SG, Newsom-Davis J. Neurological paraneoplastic syndromes in patients with small cell lung cancer. A prospective survey of 150 patients. J Neurol Neurosurg Psychiatry. 1991;54(9):764-7.

7. Dalmau J, Graus F, Posner JB. Anti-Hu-associated paraneoplastic encephalomyelitis/sensory 
neuronopathy: a clinical study of 71 patients. Medicine. 1992;71(2):59-72.

8. Plante-Bordeneuve V, Baudrimont M, Gorin NC, Gherardi RK. Subacute sensory neuropathy associated with Hodgkin's disease. J Neurol Sci. 1994;121(2):155-8.

9. Dropcho EJ. Antiamphiphysin antibodies with small-cell lung carcinoma and paraneoplastic encephalomyelitis. Ann Neurol. 1996;39(5):659-67.

10. Aoshima H, Kushida K, Okada M, Kageyama Y, Inoue $\mathrm{T}$, Tomita $\mathrm{H}$. Neuropathic arthropathy caused by paraneoplastic sensory neuropathy: a case report. Clin Orthop Relat Res. 1997;1(339):185-9.

11. Toepfer M, Schroeder M, Unger JW, Lochmüller H, Pongratz D, Müller-Felber W. Neuromyotonia, myocloni, sensory neuropathy and cerebellar symptoms in a patient with antibodies to neuronal nucleoproteins (anti-Hu-antibodies). Clin Neurol Neurosurg. 1999;101(3):207-9.

12. Behringer D, Spyridonidis A, Fetscher S, Schmitt-Gräff A, Högerle S, Kaiser R. Paraneoplastic polyneuropathy preceding the diagnosis of Hodgkin's disease and non-small cell lung cancer in a patient with concomitant Borrelia burgdorferi infection. Ann Hematol. 2001;80(4):232-5.

13. Winkler AS, Dean A, Hu M, Gregson N, Chaudhuri KR. Phenotypic and neuropathologic heterogeneity of anti-Hu antibody-related paraneoplastic syndrome presenting with progressive dysautonomia: report of two cases. Clin Auton Res. 2001;11(2):115-8.

14. Farrugia ME. Negative-antibody paraneoplastic syndrome complicating small cell carcinoma. Scott Med J. 2001;46(4):117-8.

15. Suzuki M, Kimura H, Tachibana I, Fujimura $H$, Nakatsuji Y, Sugai F, Nakamori M, Morishita H, Toru AR, Osaki T, Hayashi S. Improvement of anti-Hu-associated paraneoplastic sensory neuropathy after chemoradiotherapy in a small cell lung cancer patient. Intern Med. 2001;40(11):1140-3.

16. Camdessanché JP, Antoine JC, Honnorat J, Vial C, Petiot P, Convers P, Michel D. Paraneoplastic peripheral neuropathy associated with anti-Hu antibodies. Brain. 2002;125(1):166-75.

17. Ivanaj A, Pautier P, Rixe O, Duvillard P, Dubard T. Peripheral neuropathy in association with an ovarian dysgerminoma. Gynecol Oncol. 2003;89(1):168-70.

18. Altaha R, Abraham J. Paraneoplastic neurologic syndrome associated with occult breast cancer: a case report and review of literature. Breast $\mathrm{J}$. 2003;9(5):417-9.

19. Ogawa M, Nishie M, Kurahashi K, Kaimori M, Wakabayashi K. Anti-Hu associated paraneoplastic sensory neuronopathy with upper motor neurone involvement. J Neurol Neurosurg Psychiatry. 2004;75(7):1051-3.

20. Kiylioglu N, Meydan N, Barutca S, Akyol A. Sub-acute sensory neuronopathy as a preceding sign of recurrence in colon carcinoma. Int J Gastrointest Cancer. 2003;34(2-3):135-7.

21. Raaphorst J, Vanneste J. Numb cheek syndrome as the first manifestation of anti-Hu paraneoplastic neuronopathy. J Neurol. 2006;253(5):664-5.

22. Schilstra A, van Tuijl JH, van Suylen RJ, Faber CG, ten Velde GP. Unclassified rhabdomyosarcoma in a patient with anti-Hu syndrome. Acta Clin Belg. 2005;60(5):248-51.

23. Martin AC, Friedlander M, Kiernan MC. Paraneoplastic mononeuritis multiplex in non-small-cell lung carcinoma. J Clin Neurosci. 2006;13(5):595-8.

24. Coppens T, Van den Bergh P, Duprez TJ, Jeanjean A, De Ridder F, Sindic CJ. Paraneoplastic rhombencephalitis and brachial plexopathy in two cases of amphiphysin auto-immunity. Eur Neurol. 2006;55(2):80-3.

25. Oki Y, Koike H, Iijima M, Mori K, Hattori N, Katsuno M, Nakamura T, Hirayama M, Tanaka F, Shiraishi M, Yazaki S. Ataxic vs painful form of paraneoplastic neuropathy. Neurology. 2007;69(6):564-72.

26. Schrader C, Alwan G, Weissenborn K. Pseudochoreoathetosis can be the first clinical manifestation of anti-Hu-neuropathy associated with squamous cell carcinoma. Mov Disord. 2008;23(15):2257-9.

27. Coret F, Bosca I, Fratalia L, Perez-Griera J, Pascual A, Casanova B. Long-lasting remission after rituximab treatment in a case of anti-Hu-associated sensory neuronopathy and gastric pseudoobstruction. J Neurooncol. 2009;93(3):421-3.

28. Santangeli P, Pieroni M, Marzo F, Frontera A, Vitulano N, Luciani N, Bellocci F, Crea F. Cardiac myxoma presenting with sensory neuropathy. Int J Cardiol. 2010;143(1):e14-6.

29. Rajabally YA, Qaddoura B, Abbott RJ. Steroid-responsive paraneoplastic demyelinating neuropathy and myelopathy associated with breast carcinoma. J Clin Neuromuscul Dis. 2008;10(2):65-9.

30. Uribe-Uribe NO, Jimenez-Garduño AM, Henson DE, Albores-Saavedra J. Paraneoplastic sensory 
neuropathy associated with small cell carcinoma of the gallbladder. Ann Diagn Pathol. 2009;13(2):124-6.

31. López JL, Amezcua S, Pascual J, Algara M. Acute motor axonal neuropathy associated with anal carcinoma: paraneoplastic neurological syndrome or coincidence? Rep Pract Oncol Radiother. 2011;16(2):54-7.

32. Samarasekera S, Rajabally YA. Demyelinating neuropathy with anti-CRMP5 antibodies predating diagnosis of breast carcinoma: favorable outcome after cancer therapy. Muscle Nerve. 2011;43(5):764-6.

33. Kawanishi K, Ohyama Y, Kanai Y, Hirase T, Tanaka H, Miyatake J, Tatsumi Y, Ashida T, Nakamine H, Matsumura I. Sub-acute demyelinating polyradiculoneuropathy as an initial symptom of peripheral $\mathrm{T}$ cell lymphoma, not otherwise specified (PTCL-NOS). Intern Med. 2012;51(15):2015-20.

34. Flanagan EP, Sandroni P, Inwards DJ, Jones LK. Paraneoplastic lower motor neuronopathy associated with Hodgkin lymphoma. Muscle Nerve. 2012;46(5):823-7.

35. Porto L, Miranda M, Gomes A, André R, Rodrigues B. Paraneoplastic neurological syndrome as an initial indicator of small cell carcinoma of the lung. BMJ Case Rep. 2013;2013:bcr2012008432.

36. Tomita M, Koike H, Kawagashira Y, Iijima M, Adachi H, Taguchi J, Abe T, Sako K, Tsuji Y, Nakagawa M, Kanda F. Clinicopathological features of neuropathy associated with lymphoma. Brain. 2013;136(8):2563-78.

37. Koike H, Yoshida H, Ito T, Ohyama K, Hashimoto R, Kawagashira Y, Iijima M, Sobue G. Demyelinating neuropathy and autoimmune hemolytic anemia in a patient with pancreatic cancer. Intern Med. 2013;52(15):1737-40.

38. Hughes CL, Yorio JT, Kovitz C, Oki Y. Treatment decisions in a man with Hodgkin lymphoma and Guillian-Barré syndrome: a case report. J Med Case Rep. 2014;8(1):455.

39. Kannan MA, Challa S, Kandadai RM, Uppin MS, Jabeen SA, Borgohain R. Series of paraneoplastic vasculitic neuropathy: a rare, potentially treatable neuropathy. Neurol India. 2015;63(1):30.

40. Verschueren A, Gallard J, Boucraut J, Honnorat J, Pouget J, Attarian S. Paraneoplastic subacute lower motor neuron syndrome associated with solid cancer. J Neurol Sci. 2015;358(1):413-6.

41. Ni J, Weng L, Liu M, Yang H, Wang Y. Small cell lung cancer accompanied by tonsillar metastasis and Anti-Hu antibody-associated paraneoplastic neuropathy: a rare case report with long-term survival. Medicine (Baltimore). 2015;94(50):e2291.

42. Erdener SE, Vural A, Temucin CM, Ozdamar SE, Nurlu G, Varli K, Dericioglu N. Brachial diparesis due to motor neuronopathy as one of the predominant presenting signs of occult small cell lung carcinoma. Intern Med. 2016;55(12):1641-3.

43. Jarius S, Ringelstein M, Haas J, Serysheva II, Komorowski L, Fechner K, Wandinger KP, Albrecht P, Hefter H, Moser A, Neuen-Jacob E. Inositol 1, 4, 5 -trisphosphate receptor type 1 autoantibodies in paraneoplastic and non-paraneoplastic peripheral neuropathy. J Neuroinflamm. 2016;13(1):278.

44. Zis P, Rao DG, Wagner BE, Nicholson-Goult L, Hoggard N, Hadjivassiliou M. Cerebellar ataxia and sensory ganglionopathy associated with light-chain myeloma. Cereb Ataxias. 2017;4(1):1.

45. Candler PM, Hart PE, Barnett M, Weil R, Rees JH. A follow up study of patients with paraneoplastic neurological disease in the United Kingdom. J Neurol Neurosurg Psychiatry. 2004;75(10):1411-5.

46. Graus F, Keime-Guibert F, Reñe R, Benyahia B, Ribalta T, Ascaso C, Escaramis G, Delattre JY. Anti-Hu-associated paraneoplastic encephalomyelitis: analysis of 200 patients. Brain. 2001;124(6):1138-48.

47. Lucchinetti CF, Kimmel DW, Lennon VA. Paraneoplastic and oncologic profiles of patients seropositive for type 1 antineuronal nuclear autoantibodies. Neurology. 1998;50(3):652-7.

48. Zis P, Sarrigiannis PG, Rao DG, Hewamadduma C, Hadjivassiliou M. Chronic idiopathic axonal polyneuropathy: a systematic review. J Neurol. 2016;263(10):1903-10.

49. Kafka SP, Condemi JJ, Marsh DO, Leddy JP. Mononeuritis multiplex and vasculitis: association with anti-neutrophil cytoplasmic autoantibody. Arch Neurol. 1994;51(6):565-8.

50. Vadalouca A, Raptis E, Moka E, Zis P, Sykioti P, Siafaka I. Pharmacological treatment of neuropathic cancer pain: a comprehensive review of the current literature. Pain Pract. 2012;12(3):219-51.

51. Sykioti P, Zis P, Vadalouca A, Siafaka I, Argyra E, Bouhassira D, Stavropoulou E, Karandreas N. Validation of the Greek version of the DN4 diagnostic questionnaire for neuropathic pain. Pain Pract. 2015;15(7):627-32. 